to the medical world. By Mr. Hunter it was resorted to indiscriminately in all forms of venereal sores, and it is perhaps not surprising that his successors (excepting alwars the school of Abernethy) should have resorted to mercury as the great and universal antidote to venereal sores, whether hard or soft, whether local or constitutional. But since venereal diseases have become the subject of more critical observation, our lines of demarcation are more closely defined; and while we are compelled to resort to mercury in some forms of the disease, we as rigidly eschew it in others.

The action of mercury tends to increase the secretions of the body, and at the same time to promete absorption of morbid deposits. It cannot be said to exercise any direct influence on the poison of syphilis, but only on the effects or consequences of the poison. It is not to be considered as exercising the power of a specific, because it cannot destroy the poison. It has the power to lessen and to obtain absorption of the hard deposit, but the poison remains behind to develop itself hereafter. If it were a specific, if it possessed the power to directly neutralise the poison, a man under salivation would be unsusceptible to the influence of the disease after intercourse, which he assuredly is not. It is not very uncommon for the eruptive stage to appear during the treatment by mercury for the primary sore. I believe a conrse of mercury, if exhibited with due care and moderation, is not necessarily injurious to the health; but it is painful to read the frightful and of ten fatal extremes to which it was carried in the early part of this century. As almost a matter of course, surgeons resort to mercury in every variety of hard sore, because it would appear to be a great object to attain the absorption of the thickened or indurated mass, and to heal the ulcer upon it. But is this object so essential as it appears? Look to the evidence on this head given by many eminent members of our profession before the Admiralty Committee.* You will learn therefrom that great doubts cling to the minds of some of these eminent men whether the treatment of primary sores by mercury tends either to prolong the interval before the secondary or constitutional symptoms develop themselves, or to lessen their severity when they do appear. In whatever form you administer mercury, watch carefully its effects on the local disease and on the constitution. As the hardness subsides, reduce the dose in a relation to the infuence it appears to exercise. Avoid salivation in every stage, and maintain your patient's strength throughout. In the constitutional or eruptive stage, when it assumes the dry forms of psoriasis or of lepra, mercury is less injurious to the health in protracted cases; but employ it sparingly in all moist eruptions, vesicular, pustular, or impetiginoid. A great and valuable adjunct is ever found in iodine, and the iodide of potash, in doses from five to fifteen grains, will of ten supersede the employment of mercury entirely. It may be combined with full doses of the tincture of bark.

With this very imperfect sketch of syphilis I conclude with a brief reference to the subject of phagedæna. Do not mistake phagedæna for syphilis; and here I speak with some hesitation, knowing that the two diseases are not unfrequently confounded. Syphilis is characterised by a hard deposit, phagedæna by destruction of tissue. This destructive process is obtained by active ulceration or by sloughing; sometimes both processes are united in the same wound. Commencing from a local venereal sore, the sore extends, ulcerates rapidly, sloughs, and burrows beneath the surrounding tissue. The local actions may be destroyed by nitric acid, but the disease bursts out in the form of an eruption, which quickly develops in that of active and destructive ulceration in any part of the surface of the whole body. As to treatment, I would say, any remedy but mercury. Iodides of iron and potash, good air, ample diet, wine in moderation, and nitric acid (pure or diluted), localls applied in proportion to the activity of the destructive local actions.

* Peport of Committee. Tide evidence of Langston Parker, Jonathan Hutchinson, S. A. Lane, and others.

A Prize Essay. - The Medical Society of Bordeaux sets the following question-Are the lesions of puerperal fever contagions? 212. Essars to be sent before Aug. 31st, 1S71, to Dr. Dubreuilh, Rue Fictor, Bordeaux.
ON THE

\section{SURGICAL PRACTICE OF THE WAR.}

BY WILLIAM MAC CORMAC, F.R.C.S.,

LATE SLREBON-IN-CHIEF, ANGLO-AMERICAN AMELLANCB AT SEDAT.

Perhaps a fer general remarks on the surgical practice of the war may not at the present time be uninteresting. Unfortunately I can only comment upon what I have myself seen and done. My own work engrossed my entire time, and I regret extremely I have but little experience of what was accomplished by other surgeons, of whom there were many, and most distinguished, around me. At Sedan, where I arrived shortly before the battle, we had under our care both French and German wounded, but fewer of the latter than of the former.

The majority of the wounds were shell wounds, as we were placed in that portion of the lines most exposed to the artillery fire. However, in a considerable proportion of our patients, the zundnädelgewehr had wrought its frightful havoc, and we had a good many chassepôt wounds as well.

So far as I am able to judge, the egg-shaped bullet of the Prussian infantry inflicts the more extensive injury on both the bone and soft parts. It is considerably heavier than the French cylindro-conical ball, weighing 500 grains, as compared with 384 grains, the weight of the French projectile. It seems to pulverise the bone where it strikes it, and to splinter it extensively as well. The external wound bears but little proportion in its extent to the nature and severity of the deeper lesion when the bone is injured.

Excluding wounds of the head and trunk, flesh wounds of the limbs without fracture of the bone are quite twice as frequent as wounds accompanied by fracture. Indeed, as has been over and over again observed, it is remarkable how bullets appear to traverse without touching the bone, or other important parts, which would seem directly in their way.

Penetrating wounds of the head and abdomen are, of course, comparatively rare, the unfortunate recipients usually dying upon the field immediately, or soon after, they get them.

We saw very few cases of mitrailleuse wounds. When a soldier is wounded by musket-firing, as a general rule he receives but one bullet, falls, and, if not killed, is carried off to an ambulance. But the unfortunate men exposed to the fire of the mitrailleuse were often hit in half a dozen places at the same moment, by one volley. The mitrailleuse bullet weighs an ounce and three-quarters, and twenty-five are sent on their errand of death in each discharge. The range is about 1400 or 1500 vards, and as the balls do not spread till they have reached a considerable distance, the troops within range are often literally riddled. Between Balon and Bazeilles there were quite a number of Bavarian soldiers lying dead with their limbs almost carried away, in some iustances, so terribly were they torn up by mitrailleuse discharges. In many parts of the field I saw men with large portions of the skull blown away-a most ghastly sight; others as instantaneously shot dead through different parts of the trunk.

One remarkable, and, I believe, much disputed fact, I am able to verify from personal observation. I can myself afford no explanation, indeed it is to me inexplicable. The majority of those killed whom I saw upon the field were lying on the back with their arms and legs extended, as if they had died with every muscle relaxed; but there was a certain number, I am sure I saw eight or ten, who were lying with both arms rigidly fixed in a constrained positionsuch an attitude, in short, as they would have held if they were about to raise their guns to the shoulder to fire. Had the muscles relaxed in these cases, at or after death, the force of gravity must have caused their limbs to fall extended like the rest; but it was not so. This was on September 4 th, three clear days after the battle.

With reference to the wounded under our care, although we were placed under exceptionally favourable circumstances for a field ambulance, the results are, and must be, far from being so satisfactory as one could wish. 
After the battles at Sedan of the 31st August and the 1st September, our beds, 384 in number, filled as if by magic. All the cases were most severe ones, and it was impossible all at once to overtake the huge press of work suddenly thrust upon us. The numbers of cases and operations we had have already been alluded to in The LANCET. I give them in the subjoined collective form.

\section{Caserne D'Asfeld, Sedon.}

Wounded, inscribed and registered, including a few sick

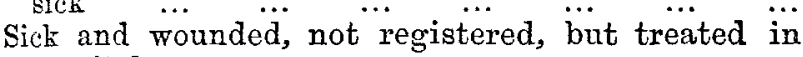
hospital ...

Wounded, dressed and attended to as extra patients, during the battles of the 31st August and 1st September

$$
\begin{array}{ccccc}
\text { Total } & \ldots & \ldots & \ldots & \overline{1193} \\
\text { Table of Injuries. } & & & &
\end{array}
$$

Gunshot wounds of the head, face, and neck

Gunshot wounds, without penetration, of the trunk... $\quad \ldots \quad \ldots \quad \ldots \quad \ldots$

Penetrating wounds of the chest $\quad \cdots$

$\begin{array}{lll}\prime \prime & \text { abdomen } & \ldots \\ \text { " } & \text { pelvis } & \ldots \\ \text { " joints } & \ldots\end{array}$

Gunshot wounds around joints, close to, but not penetrating, chiefly the knee

Gunshot wounds, causing fracture of the bones of the extremities

Gunshot wounds of the extremities without fracture

Gunshot wounds of the hand and foot...

Sprains, burns, contusions, \&c. ... ...

\section{Table of Operations.}

Disarticulation of joints, including two hip-joint and three knee-joint amputations

Amputations of limbs, including fourteen thigh, nineteen leg, and two double amputations

Resections of joints, including one knee, two shoulder, and nine elbow cases, and a double resection of shoulder and elbow, as well as resections of the long bones

Ligature of the subclavian artery $\quad \cdots$ Ligature of the common carotid artery Ligature of the common femoral artery... Ligature of the dorsalis pedis artery .. (All for secondary hæmorrhage.)

o. of Cases. Deaths. $\begin{array}{lll}38 & \ldots \ldots & 10\end{array}$

$29 \quad \ldots . . .4$ $21 \quad \ldots \ldots .10$ 5 …. 5

9 ...... 4 $\begin{array}{llll}35 & \ldots \ldots & 21\end{array}$

$25 \quad \ldots \ldots . \quad 1$

$91 \quad \ldots \ldots .35$

$\begin{array}{lll}136 & \ldots . . & 9\end{array}$

55

$28 \quad \ldots . .61$

o. of Cases. Deaths.

77

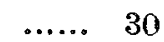

$\begin{array}{rrr}15 & \cdots \cdots & 7 \\ 2 & \cdots \cdots & 2 \\ 2 & \cdots \cdots & 1 \\ 1 & \cdots \cdots & 1 \\ 1 & \cdots \cdots & 0\end{array}$

No doubt the number of deaths here tabulated is large, but it is by no means excessive. Of one thing I am sure: our ventilation was excellent, and most strictly attended to, and we used carbolic acid very freely. There was thorough cross-ventilation, and the wind blew in at one side of the ward, and out at the other, often so strongly as to make the patients complain.

I ascribe the majority of the deaths to pyæmia. We had no hospital gangrene whatever, or any other evidence of so-called hospitalism. I have noted pyæmia with metastatic abscess in the liver and lungs as the cause of death in thirty-four instances; but I feel confident that I have omitted to register many cases where this was the cause. In the large majority of instances in which pyæmia supervened there had either been a gunshot fracture of some of the bones or an amputation. There were, however, several cases of fatal pyæmia occurring after simple flesh wounds. I believe the outbreak of pyrmia amongst us had a close connexion with the influx of very bad cases on the 9 th and 12th September, on which dates 195 new patients were sent to us.

Taking ten or twelve days as the mean duration of an attack of acute pyæmia terminating in death, we should expect a large mortality from this cause shortly after the 20th September. I find, on looking over my notes, that 20 of the 34 cases of death from pyæmia occurred between the 19th and 27 th of September, and that as many as 11 deaths took place from pyæmia alone on the days of the 21st and 22nd September. This would surely indicate the overcrowding during the week following the 9th September as having a very close relationship with the subsequent outbreak of blood-poisoning.

A glance over the list of operations will show but one case of excision of the knee. It was the only case I was able to select favourable in all respects for this operation, and the patient speedily died. Professor Nussbaum, of Munich, attached in a high position to the German army, has had the hardihood to perform thirty-six times resection of the knee for gunshot wound. Of the thirty-six, thirtyfive died, and amputation of the thigh was performed in the thirty-sixth case with a rapidly fatal result. In the Crimean war, and in the American war, the results of excision for gunshot injury of the knee have been alike most unsatisfactory. Unce only I performed excision myself, because the case appeared to afford the most favourable prospect of success; but I now question if almost any case, however tempting, would make me perform resection of the knee-joint for gunshot injury in war.

There are twenty-five cases mentioned in the table of wounds around joints, chiefly the knee. I was much struck by the number of cases of this kind, which bear a very large proportion to the number of penetrating wounds of the joints. Often have I seen a bullet track go quite half round the knee-joint, without opening the articulation. These cases, I need scarcely add, got well just like simple flesh wounds elsewhere. Possibly this fact may help to account for the prodigious percentage of cures of penetrating wounds of the knee, as much as 50 per cent., which some of the surgeons during the late war in America were fortunate enough to secure.

There are many other points of interest in connexion with the cases which came under my notice, to which I might advert, but, for the present at least, I have sufficiently trespassed upon the pages of THE LANCET. Nov. 1 st, 1870 .

\section{THE NEW DIPLOMA IN STATE MEDICINE}

\section{BY HENRY W. RUMSEY, M.D.}

A sTATEMENT recently published by authority of the University of Dublin, deseribing the new qualification in State Medicine, is one not only of great interest to the younger members of the profession, but also of vast importance to the public welfare, as well as to the future position and usefulness of the whole medical body.

Nearly six years ago it was proposed* that the universities should take independent action in this matter, by instituting new degrees or diplomas in State Medicine. A committee, appointed in 1867 by the British Medical Association, addressed a memorial on this subject, dated April, 1868, to the president and members of the General Medical Council. At this stage of the movement it may be as well to reproduce that document, as follows:-

"That, whereas there is at the present time no sufficient guarantee for the general competency, or the special qualification, of medical men appointed as officers of health, or employed as medical jurists; no recognised plan for conducting their education; nor any examining body for regulating the standard, and testing the sufficiency, of their acquirements, - the members of this committee earnestly urge upon the Medical Council to consider, at their next meeting, the special qualifications required for such medical officers of health, and the mode in which they should be trained and licensed for the discharge of their varied and important duties."

Accordingly, in the succeeding session, Dr. Acland brought the question before the Medical Council, and procured the appointment of a committee "to report on the steps proper to be taken, if any, for granting diplomas or certificates of proficiency in State Medicine, and for recording the same

* "A Proposal for the Institution of Degrees or Cer'ifieates of Qualitication in State Medicine by the Universilies of the United Kingdom." (London: Macmillan. 1865.) In 1568 Dr. Rumsey published auothe. paper on the "Educational Aspects of State Medicine" 